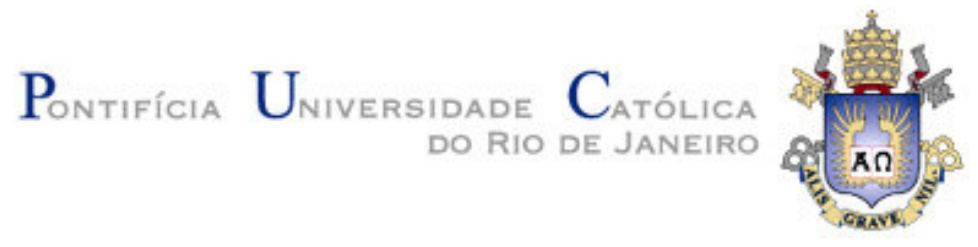

Louise dos Santos Erasmi Lopes

\title{
Análise do Comportamento Mecânico e Ambiental de Misturas Solo-Cinzas de Carvão Mineral para Camadas de Base de Pavimentos
}

Dissertação de Mestrado

Dissertação apresentada ao Programa de Pós-graduação em Engenharia Civil da PUC-Rio como requisito parcial para obtenção do grau de Mestre em Engenharia Civil.

Orientadora: Michéle Dal Toé Casagrande Co-orientadora:Laura Maria Goretti da Motta 


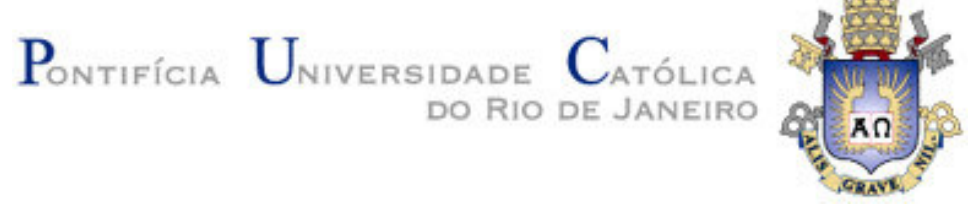

\title{
Louise dos Santos Erasmi Lopes
}

\section{Análise do Comportamento Mecânico e Ambiental de Misturas Solo-Cinzas de Carvão Mineral para Camadas de Base de Pavimentos}

Dissertação apresentada como requisito parcial para obtenção do grau de Mestre pelo Programa de Pósgraduação em Engenharia Civil da PUC-Rio. Aprovada pela Comissão Examinadora abaixo assinada.

\author{
Prof ${ }^{a}$. Michéle Dal Toé Casagrande \\ Orientadora \\ Departamento de Engenharia Civil - PUC-Rio \\ Profa. Laura Maria Goretti da Motta \\ Co-orientadora \\ COPPE/UFRJ
}

Dr. Antônio Carlos Rodrigues Guimarães

IME/RJ

Prof. Eurípedes do Amaral Vargas Jr Departamento de Engenharia Civil - PUC-Rio

Prof. José Eugenio Leal Coordenador Setorial do Centro Técnico Científico - PUC-Rio 
Todos os direitos reservados. É proibida a reprodução total ou parcial do trabalho sem autorização da universidade, da autora, da orientadora.

\section{Louise dos Santos Erasmi Lopes}

Graduou-se em Engenharia Civil com ênfase em ambiental pela PUC-Rio (Pontifícia Universidade do Rio de Janeiro) em dezembro de 2008. Ingressou no mestrado na PUC-Rio em março de 2009, desenvolvendo dissertação na linha de pesquisa de reutilização de resíduos para Pavimentação.

Ficha Catalográfica

Lopes, Louise dos Santos Erasmi

Análise do comportamento mecânico e ambiental de misturas solo-cinzas de carvão mineral para camadas de base de pavimentos / Louise dos Santos Erasmi Lopes ; orientadora: Michéle Dal Toé Casagrande ; co-orientadora: Laura Maria Goretti da Motta. -2011.

208 f. : il. (color.) ; $30 \mathrm{~cm}$

Dissertação (mestrado)-Pontifícia Universidade Católica do Rio de Janeiro, Departamento de Engenharia Civil, 2011.

Inclui bibliografia

1. Engenharia civil - Teses. 2. Cinzas de carvão mineral. 3. Cinza volante. 4. Cinzas de fundo. 5. Cal. 6. Estabilização de solos. 7. Base de pavimentos. 8. Materiais alternativos. I. Casagrande, Michelé Dal Toé. II. Motta, Laura Maria Goretti da. III. Pontifícia Universidade Católica do Rio de Janeiro. Departamento de Engenharia Civil. IV. Título.

CDD: 658 
Aos meus pais, Helcio e Paula, aos meus irmãos, Edgard e Hellen, e ao meu amor, Diego, pelo amor, compreensão e incentivo. 


\section{Agradecimentos}

A Deus, por tudo.

Aos meus pais, Helcio e Paula, que dedicaram suas vidas a mim e meus irmãos, nos dando muito mais que amor e carinho. Sem vocês nada disso seria possível. Faltam-me palavras para descrever o amor que sinto por nossa família.

Ao Edgard, meu irmão, pela amizade incontestável, pelos abraços, colos e sábios conselhos nos momentos em que mais precisei. A Hellen, minha irmã, por toda compressão, companhia e sinceridade acima de tudo. Vocês são essenciais em minha vida, amo vocês.

Ao Diego, por tudo que já vivemos juntos. Por ser muito mais que namorado, meu maior incentivador, meu amigo, por sempre acreditar em mim e me fazer persistir em busca dos meus sonhos. Amo você. Obrigada por estar sempre ao meu lado, por vibrar comigo, me consolar nos momentos difíceis, por todo o carinho e amor.

A minha avó Dyla, por todo carinho, por ser "minha fã número 1", como ela mesma diz. A minha avó Wilma, que mesmo não estando mais aqui, se faz presente, por todos os seus inesquecíveis abraços e "cartinhas".

A professora e amiga Michéle Casagrande pela orientação do meu trabalho, por todo o conhecimento transmitido, que muitas vezes saíam do campo técnico da Engenharia Civil, levarei comigo ao longo de toda minha vida. Sobretudo a toda dedicação e paciência em me atender nos momentos de dúvidas e questionamentos, sem a sua compreensão e apoio o caminho teria sido muito mais árduo.

A minha co-orientadora, professora Laura Motta, pela incontestável competência e seriedade no exercício de sua profissão. Sobretudo por todo o apoio em permitir 
a utilização dos laboratórios da COPPE/UFRJ, permitindo a realização da presente pesquisa.

Um agradecimento especial a Mariluce Ubaldo, pelos conselhos e ajuda na elaboração deste trabalho. Aos técnicos de laboratório da COPPE/UFRJ, Washington, Thiago, Allan, Leandro, Carlinhos, Luizão e Beto que sempre estiveram prontos a me ajudar.

A todos os meus amigos por compreenderem os momentos de ausência. E por estarem sempre ao meu lado. A Mariana e a Priscila, "desde sempre e para sempre", que este continue sendo o nosso "lema" até ficarmos bem velhinhas.

Aos amigos da PUC-Rio, em especial para a turma da salinha 614L, Rick, Paulinha, Thiaguinho, Carnavale e Eric, pelas risadas nos momentos de descontração e todo o apoio nos momentos de estudo. À Fernanda e à Paloma, pelo companheirismo e incentivo durante toda faculdade e mestrado.

A Luciana Szeliga e Priscila Vargas, alunas de iniciação científica que tanto me ajudaram na realização dos ensaios.

Ao Professor Alberto Sayão, que acreditou em mim, me apoiando na decisão de fazer o Mestrado.

A Luciana Garavaglia e Mirleni Amboni, da SATC, que gentilmente forneceu as cinzas que foram utilizadas no estudo.

A todos os professores da engenharia civil da PUC-Rio com os quais tive o prazer de conviver e aprender durante a graduação e o mestrado.

Aos funcionários do departamento, pela colaboração ao longo dos anos na PUCRio e pelo convívio prazeroso.

A CNPq pela concessão das bolsas de estudo. 


\section{Resumo}

Lopes, Louise dos Santos Erasmi; Casagrande, Michéle Dal Toé (Orientadora); Motta, Laura Maria Goretti (Co-orientadora). Análise do Comportamento Mecânico e Ambiental de Misturas SoloCinzas de Carvão Mineral para Camadas de Base de Pavimentos. Rio de Janeiro, 2011. 208 p. Dissertação de Mestrado. Departamento de Engenharia Civil, Pontifícia Universidade Católica do Rio de Janeiro.

Este estudo apresenta a caracterização de dois tipos de cinzas (de fundo e volante) obtidas da queima de carvão mineral em usinas termelétricas, tendo como objetivo avaliar sua aplicabilidade em camadas de base de pavimentos rodoviários, através da mistura destas cinzas a um solo areno-siltoso não-laterítico característico do estado do Rio de Janeiro. Foram realizados ensaios de caracterização física (granulometria e limites de Atterberg), química (fluorescência de raio-X por energia dispersiva), mecânica (compactação, módulo de resiliência e deformação permanente) e, por se tratar da utilização de resíduos industriais, ensaios ambientais de solubilização e lixiviação. Tais ensaios foram realizados para o solo puro e para as misturas de solo-cinza de fundo (30 e $40 \%$ de cinzas de fundo) e solo-cinza volante (10 e $20 \%$ de cinza volante), sendo estes teores relacionados ao peso do solo seco. Também foram ensaiados corpos de provas com a adição de 3\% cal. Baseando-se nos dados resultantes dos ensaios mecânicos foi realizado o dimensionamento mecanístico-empírico para uma estrutura típica de pavimento. As misturas com inserção de cinzas apresentaram um comportamento mecânico compatível com as exigências de um pavimento de baixo volume de tráfego. Os resultados obtidos demonstram que o solo em estudo é dependente da tensão confinante e que a inserção de cinza volante e a cura prévia aumentam consideravelmente o valor do módulo de resiliência, o que resulta na diminuição da espessura da camada de base em comparação ao solo puro, para um mesmo nível 
de carregamento e mesmos critérios de dimensionamento. Os resultados com as cinzas de fundo também apresentaram resultados satisfatórios, aumentando o valor do módulo de resiliência, apesar de em menores taxas do que as cinzas volantes, no caso das misturas com a presença de cal e, contudo, nas misturas sem a adição de cal, obtendo melhores resultados ao serem comparados com as misturas com a presença das cinzas volantes. Os resultados obtidos foram satisfatórios, sendo dependentes do teor e do tipo de cinza utilizado, da presença da cal, além do tempo de cura. Tais fatos, juntamente com os resultados dos ensaios ambientais ressaltam o emprego positivo de ambos os tipos de cinzas (de fundo e volante) de carvão mineral para aplicação em camadas de base de pavimentos rodoviários, minimizando problemas atuais de disposição de resíduos em lixões e aterros sanitários, dando um fim mais nobre a este material.

\section{Palavras-chave}

Cinzas de Carvão Mineral; Cinza Volante; Cinzas de Fundo; Cal; Estabilização de Solos; Base de pavimentos; materiais alternativos. 


\section{Abstract}

Lopes, Louise dos Santos Erasmi; Casagrande, Michéle Dal Toé (Advisor); Motta, Laura Maria Goretti (Co-Advisor). Analysis of Mechanical and Environmental Behavior of Ash-Soil Mixtures of Coal Base Layers for Pavements. Rio de Janeiro, 2011. 208 p. MSc. Report - Departamento de Engenharia Civil, Pontifícia Universidade Católica do Rio de Janeiro.

The research consists in examining the applicability of two kinds of ash (fly and bottom) of coal combustion residue from thermal power, on the layers of pavements base road by mixing these ashes with a nonlateritic sandy-silty soil, characteristic of the Rio de Janeiro state, with and without lime addiction. This study presents the results of physical characterization (granulometry and Atterberg limits), chemistry (fluorescence X-ray energy dispersive), and mechanics (compression, resilient modulus and permanent deformation), and considering that ashes are industrial waste, environmental testing solubilization and leaching. These tests were conducted on the pure soil, on the ashes and on soil with bottom ash (30 and $40 \%$ of bottom ash) and fly ash (10 and $20 \%$ of fly ashes) mixtures, these levels of ashes are related to the weight of dry soil, with and without lime addiction. The composite model for resilient modulus were obtained, which represents the mechanical behavior, using the finite element program (SisPAV) for the pavement design. The mixtures with the addiction of ashes showed a mechanical behavior consistent with the requirements for low traffic roads. The results show that the soil is dependent on confining pressure and the inclusion of fly ash and the mixture cure dramatically increase the value of resilient modulus, which is revealed by thinner base layer in comparison to the pure soil, for the same load level and the same design criteria. The results of bottom 
ashes also were aceptable, increasing the value of resilient modulus in lower taxes than the fly ashes with the addiction of lime, but showing better results in the mixtures without addiction of lime, when comparing wiht the mixtures with fly ashes. The results were satisfactory, and dependents of the levels and kind of ashes, of addiction of lime, and the cure, highlighting the use of both ashes of mineral coal in pavement base roads, eliminating the current problems of waste disposal in dumps and landfills, putting a best end for this material.

\section{Keywords}

Coal ash; fly ash; bottom ash; lime; soil stabilization; pavement base; alternative materials. 


\section{Sumário}

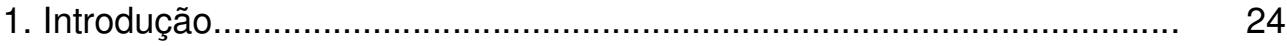

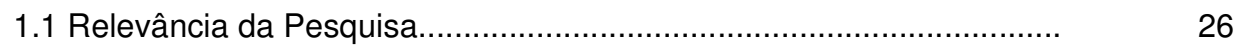

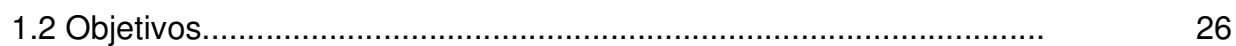

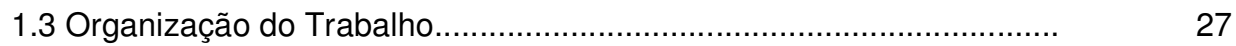

2. Revisão Bibliográfica...................................................................... 29

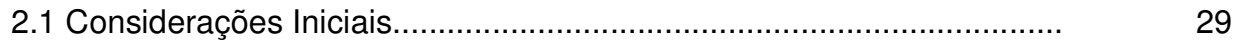

2.2 Carvão Mineral e Sua Importância na Matriz Energética Brasileira........... 30

2.3 Origem e Classificação das Cinzas................................................... 32

2.3.1 Cinza Volante......................................................................

2.3.2 Cinza de Fundo..................................................................

2.4 Aproveitamento das Cinzas de Carvão Mineral....................................... 38

2.4.1 Aproveitamento das Cinzas de Carvão Mineral na Pavimentação . 40

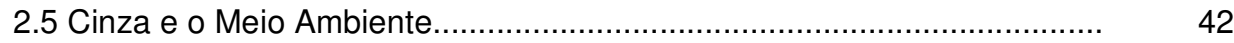

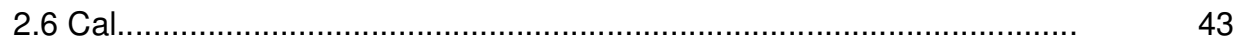

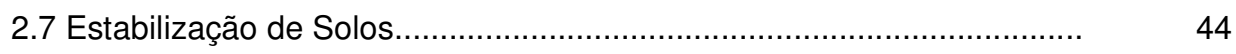

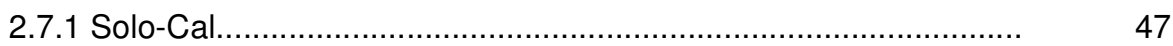

2.7.2 Solo-Cinza Volante.............................................................. 54

2.7.3 Solo-Cinza de Fundo ............................................................

2.7.4 Solo-Cinzas de Resíduos Sólidos Urbanos...................................... 57

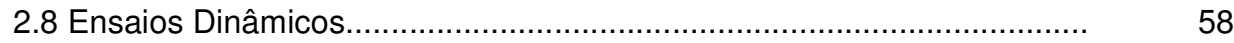

2.8.1 Ensaio Triaxial de Cargas Repetidas - Módulo de Resiliência........... 61

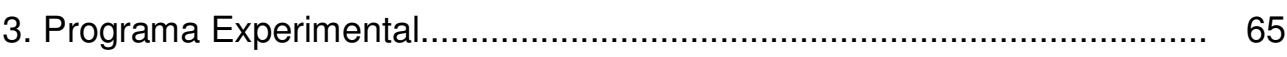

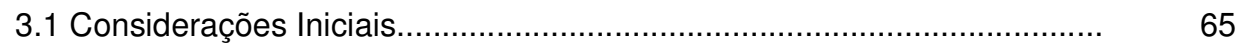

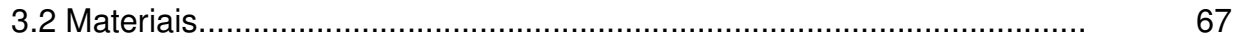




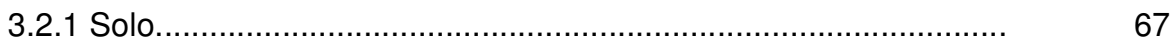

3.2.2 Cinzas Volante e de Fundo........................................................... 26

3.2.2.1 Complexo Termelétrico Jorge Lacerda........................... $\quad 72$

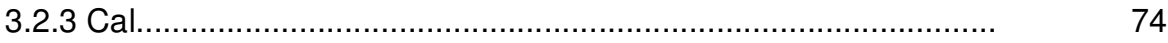

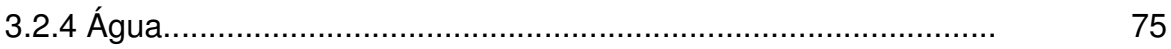

3.2.5 Misturas Solo-Cinza-Cal........................................................

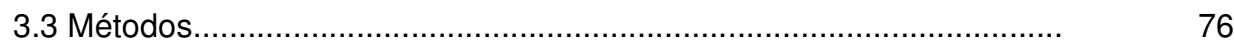

3.3.1 Coleta e Preparação das Amostras................................................... 78

3.3.2 Ensaios de Caracterização Física................................................. 78

3.3.2.1 Limites de Atterberg.................................................. $\quad 79$

3.3.2.2 Massa Específica dos Grãos........................................... 79

3.3.2.3 Análise Granulométrica............................................... $\quad 80$

3.3.3 Ensaios de Caracterização Química e Ambiental.............................. 81

3.3.3.1 Composição Química................................................. $\quad 81$

3.3.3.2 Teor de Matéria Orgânica............................................... $\quad 81$

3.3.3.3 Ensaios de Solubilização e Lixiviação................................ 82

3.3.4 Ensaios de Caracterização Mecânica.............................................. 83

3.3.4.1 Ensaio de Compactação................................................ 83

3.3.4.2 Ensaio de Módulo de Resiliência ou Resiliente.................. 84

3.3.4.3 Ensaio de Deformação Permanente.................................. 92

3.3.5 Dimensionamento do Pavimento Típico........................................... 94

4. Apresentação dos Resultados............................................................ 97

4.1 Considerações Iniciais........................................................................ 97

4.2 Ensaios de Caracterização Física....................................................... 97

4.2.1 Limites de Atterberg.................................................................

4.2.2 Massa Específica dos Grãos........................................................ 97

4.2.3 Análise Granulométrica................................................................ 99 
4.2.3.1 Classificação SUCS............................................ 101

4.2.3.2 Classificação HRB................................................ 101

4.3 Ensaios de Caracterização Química e Ambiental................................ 103

4.3.1 Composição Química.................................................... 103

4.3.2 Teor de Matéria Orgânica....................................................... 106

4.3.3 Ensaios de Solubilização e Lixiviação....................................... 107

4.4 Ensaios de Caracterização Mecânica.......................................... 110

4.4.1 Ensaio de Compactação................................................ 110

4.4.2 Ensaio de Módulo de Resiliência ou Resiliente.................................. 118

4.4.2.1 Influência do Tempo de Cura................................... 122

4.4.2.2 Influência do Teor e do Tipo de Cinzas........................... 128

4.4.2.3 Influência da Cal nas Misturas com Cinzas de Fundo e 135 Volante.

4.4.3 Ensaio de Deformação Permanente....................................... 140

4.4.3.1 Influência do Tempo de Cura..................................... 142

4.4.3.2 Influência do Teor e do Tipo de Cinzas.......................... 145

4.5 Dimensionamento do Pavimento Típico......................................... 148

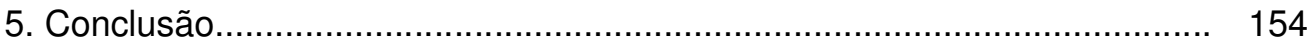

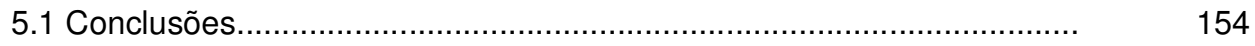

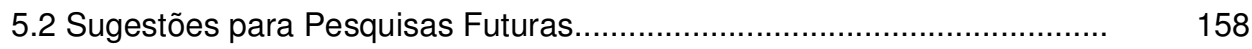

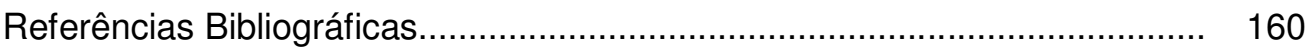

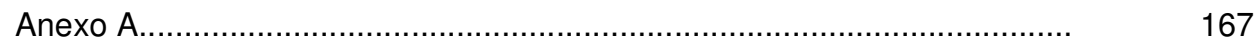

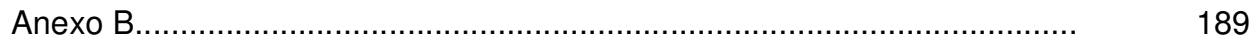

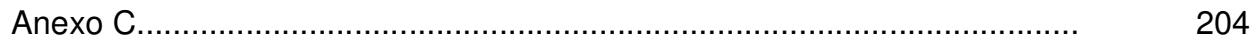




\section{Lista de figuras}

Figura 1.1: Bacia de sedimentação de Cinzas do Complexo Termelétrico de Jorge Lacerda (Fonte: LEANDRO, 2005).

Figura 2.1: Gráfico representativo da Oferta Interna de Energia no Brasil com dados de 2009 (Fonte: EPE, 2010)

Figura 2.2 : Comparação das Diferentes Fontes de Energia, no Brasil, em 2008 e 2009 (Fonte: EPE, 2010)

Figura 2.3: Processo de Queima do Carvão Mineral em Usinas Termelétricas (Fonte: Farias, 2005).

Figura 2.4: Moldagem de Peças de Concreto para Pavimentação com uso de cinza.......

Figura 2.5: Mecanismos de Estabilização Solo-Cal (Fonte: Inglês \& Metcalf, 1972 apud Rosa, 2009)

Figura 2.6 : Efeito do teor de cal sobre a resistência a compressão simples para alguns solos tratados com cal e curados por 7 dias (Fonte: Rosa, 2009).

Figura 2.7: Efeito do tempo de cura sobre a resistência à compressão simples para alguns tipos de solos estabilizados com cal (Fonte: Rosa, 2009)

Figura 2.8 : Equipamento do Ensaio Triaxial de Cargas Repetidas do Laboratório de Geotecnia e Pavimentos da COPPE/UFRJ usado no presente estudo

Figura 3.1 : Destaque ao Mapa Pedológico do Estado do Rio de Janeiro na área de estudo (Fonte: DRM-RJ).

Figura 3.2: Imagem Aérea da Localização da Jazida em Campo Grande (Fonte: Google Maps, 2010).

Figura 3.3: Aspectos da jazida utilizada para obter o solo deste estudo ressaltando sua heterogeneidade.

Figura 3.4: Detalhe da amostra do Solo utilizado neste estudo após secagem e destorroamento

Figura 3.5: Localização do Complexo Termelétrico Jorge Lacerda (Fonte: Leandro, 2005).

Figura 3.6 : Aspecto da Cinza de Fundo utilizada no presente estudo.

Figura 3.7 : Aspecto da Cinza Volante utilizada no presente estudo.

Figura 3.8: Vista Geral do Complexo Termelétrico Jorge Lacerda (Fonte: site da Tractebel Energia, www2.tractebelenergia.com.br/, consultado no dia 14/09/2010)

Figura 3.9: Capacidade instalada TRACTEBEL ENERGIA, set 2010 (Fonte: site da Tractebel Energia, www2.tractebelenergia.com.br/, consultado no dia 14/09/2010)

Figura 3.10: Etapa referente à Caracterização dos Materiais 
Figura 3.11: Etapa referente à caracterização mecânica e ambiental.

Figura 3.12: Compactador Mecânico da COPPE/UFRJ e o molde tripartido utilizado.

Figura 3.13: Esquema llustrativo do Equipamento de Ensaios Triaxiais de Carga Repetida (Fonte: Medina \& Motta, 2005).

Figura 3.14: Molde tripartido 10 X 20cm, para compactação dos corpos-de-prova

Figura 3.15: Montagem do Equipamento do Ensaio Triaxial de Cargas Repetidas da COPPE/UFRJ.

Figura 3.16: Exemplo de Preparação dos corpos-de-prova após ensaio para Cura em Câmara Úmida desta pesquisa...

Figura 3.1: Fluxograma de Desenvolvimento do SisPav (Fonte: Franco,2007)....

Figura 3.28: Estrutura do Pavimento Típico adotada para a análise mecanísticaempírica (Fonte: Vizcarra,2010)....

Figura 4.3.a: Variação da Massa Específica dos Grãos com o teor de cinza de Fundo.

Figura 4.1.b: Variação da Massa Específica dos Grãos com o teor de cinza Volante.

Figura 4.4: Curvas Granulométricas dos materiais estudados.

Figura 4.5: Curvas de Compactação do Solo, Cinza Pesada e Misturas com Cinzas de Fundo deste estudo

Figura 4.4: Curvas de Compactação típicas de Cinzas de Fundo (Fonte: Lovell et al., 1991)

Figura 4.56: Curva de Compactação da Cinza de Fundo do Complexo Termelétrico de Jorge Lacerda (Fonte: Ubaldo, 2005).

Figura 4.7: Curvas de Compactação de Solos típicos do Brasil (Fonte: Pinto, 2002).

Figura 4.7: Curvas de Compactação do Solo, Cinza Volante e Misturas com Cinza Volante do presente estudo.

Figura 4.8: Curva de Compactação da Cinza Volante do Complexo Termelétrico de Jorge Lacerda (Fonte: Ubaldo, 2005).

Figura 4.8: Curvas de Compactação de Misturas Solo-Cinza Volante-Cal por Nardi (Fonte: Nardi,1975).

Figura 4.10: Variação da Massa Esp. Aparente Seca Máxima com o teor de Cinza de Fundo do presente estudo.

Figura 4.11: Variação da Massa Esp. Aparente Seca Máxima com o teor de Cinza Volante do presente estudo.

Figura 4.12: Variação da Umidade Ótima com o teor de Cinza de Fundo 
Figura 4.13: Variação da Úmida Ótima com o teor de Cinza Volante.

Figura 4.149: Variação do Módulo de resiliência vs. Tensão Confinante para Mistura S70/CF27/C3 para os diferentes tempos de cura.

Figura 4.10: Variação do Módulo de resiliência vs. Tensão Confinante para Mistura S60/CF37/C3 para os diferentes tempos de cura.

Figura 4.11: Variação do Módulo de resiliência vs. Tensão Confinante para Mistura S90/CV7/C3 para os diferentes tempos de cura

Figura 4.17: Variação do Módulo de resiliência VS. Tensão Confinante para Mistura S80/CV27/C3 para os diferentes tempos de cura.

Figura 4.12: Variação do Módulo de resiliência vs. Tensão Confinante para Mistura S70/CF30 para os diferentes tempos de cura......

Figura 4.19: Variação do Módulo de resiliência vs. Tensão Confinante para Mistura S60/CF40 para os diferentes tempos de cura......

Figura 4.20: Variação do Módulo de resiliência vs. Tensão Confinante para Mistura S90/CV10 para os diferentes tempos de cura.

Figura 4.21: Variação do Módulo de resiliência vs. Tensão Confinante para Mistura S80/CV20 para os diferentes tempos de cura.....

Figura 4.22: Influência do Teor de Cinza de Fundo nas Misturas S70/CF27/C3 e S60/CF37/C3 no tempo de cura de 0 dias.

Figura 4.23: Influência do Teor de Cinza de Fundo nas Misturas S70/CF27/C3 e S60/CF37/C3 no tempo de cura de 28 dias.

Figura 4.24: Influência do Teor de Cinza de Fundo nas Misturas S70/CF27/C3 e S60/CF37/C3 no tempo de cura de 90 dias.

Figura 4.13: Influência do Teor de Cinza Volante nas Misturas S90/CV7/C3 e S80/CV17/C3 no tempo de cura de 0 dias.

Figura 4.26: Influência do Teor de Cinza Volante nas Misturas S90/CV7/C3 e S80/CV17/C3 no tempo de cura de 7 dias.

Figura 4.27: Influência do Teor de Cinza Volante nas Misturas S90/CV7/C3 e S80/CV17/C3 no tempo de cura de 28 dias.

Figura 4.28: Influência do Teor de Cinza Volante nas Misturas S90/CV7/C3 e S80/CV17/C3 no tempo de cura de 90 dias.

Figura 4.29: Influência do Teor de Cinza de Fundo nas Misturas S70/CF30 e S60/CF40 no tempo de cura de 0 dias.

Figura 4.30: Influência do Teor de Cinza de Fundo nas Misturas S70/CF30 e S60/CF40 no tempo de cura de 90 dias...

Figura 4.31: Influência do Teor de Cinza Volante nas Misturas S90/CV10 e S80/CV20 no tempo de cura de 0 dias.

Figura 4.32: Influência do Teor de Cinza Volante nas Misturas S90/CV10 e S80/CV20 no tempo de cura de 35 dias. 
Figura 4.33: Influência do Teor de Cinza Volante nas Misturas S90/CV10 e S80/CV20 no tempo de cura de 90 dias.

Figura 4.34: Influência da Cal nas Misturas S70/CF27/C3 e S70/CF30 com 0 dias de cura.

Figura 4.14: Influência da Cal nas Misturas S70/CF27/C3 e S70/CF30 com 28 e 35 dias de cura, respectivamente.

Figura 4.36: Influência da Cal nas Misturas S70/CF27/C3 e S70/CF30 com 90 dias de cura

Figura 4.37: Influência da Cal nas Misturas S60/CF37/C3 e S60/CF40 com 0 dias de cura.

Figura 4.38: Influência da Cal nas Misturas S60/CF37/C3 e S60/CF40 com 28 e 35 dias de cura, respectivamente.

Figura 4.39: Influência da Cal nas Misturas S60/CF37/C3 e S60/CF40 com 90 dias de cura

Figura 4.40: Influência da Cal nas Misturas S90/CV7/C3 e S90/CV10 com 0 dias de cura.

Figura 4.41: Influência da Cal nas Misturas S90/CV7/C3 e S90/CV10 com 28 e 35 dias de cura, respectivamente.

Figura 4.42 - Influência da Cal nas Misturas S90/CV7/C3 e S90/CV10 com 90 dias de cura.....

Figura 4.43: Influência da Cal nas Misturas S80/CV17/C3 e S80/CV20 com 0 dias de cura.

Figura 4.44: Influência da Cal nas Misturas S80/CV17/C3 e S80/CV20 com 28 e 35 dias de cura, respectivamente.

Figura 4.45: Influência da Cal nas Misturas S80/CV17/C3 e S80/CV20 com 90 dias de cura.

Figura 4.46: Efeito de Tempo de Cura na Deformação Permanente da Mistura S70/CF27/C3.

Figura 4.47: Efeito do Tempo de Cura na Deformação Permanente da Mistura S60/CF37/C3.

Figura 4.48: Efeito do Tempo de Cura na Deformação Permanente da Mistura $\mathrm{S} 90 / \mathrm{CV} 7 / \mathrm{C} 3$

Figura 4.49: Efeito do Tempo de Cura na Deformação Permanente na Mistura $\mathrm{S} 80 / \mathrm{CV} 17 / \mathrm{C} 3$

Figura 4.50: Influência do Teor de Cinza de Fundo nas Misturas S70/CF27/C3 e S60/CF37/C3 na Deformação Permanente com cura de 7 dias.

Figura 4.51: Influência do Teor de Cinza de Fundo nas Misturas S70/CF27/C3 e S60/CF37/C3 na Deformação Permanente com cura de 28 dias...

Figura 4.52: Influência do Teor de Cinza de Fundo nas Misturas S70/CF27/C3 e S60/CF37/C3 na Deformação Permanente com cura de 90 dias. 
Figura 4.53: Influência do Teor de Cinza Volante nas Misturas S90/CV7/C3 e S80/CV17/C3 na Deformação Permanente com cura de 7 dias.

Figura 4.54: Influência do Teor de Cinza Volante nas Misturas S90/CV7/C3 e S80/CV17/C3 na Deformação Permanente com cura de 28 dias.............................

Figura 4.15: Influência do Teor de Cinza Volante nas Misturas S90/CV7/C3 e S80/CV17/C3 na Deformação Permanente com cura de 90 dias...........................

Figura 4.16 - Estrutura do Pavimento adotada no SisPav (Fonte: Vizcarra, 2010)..

Figura 4.17: Características do Tráfego adotado no SisPav para um dos períodos de projeto (Fonte: Vizcarra, 2010)

Figura 4.18: Características do Clima adotadas no SisPav neste estudo.

Figura 4.19 - Variação das espessuras da camada de base em função do período de projeto. 


\section{Lista de tabelas}

Tabela 3.1 : Descrição e Quantidades dos Ensaios................................................ 66

Tabela 3.2: Composição e Teores das Misturas estudadas nesta pesquisa.............. 76

Tabela 3.3a: Datas e tempos de cura dos corpos-de-prova do Ensaio de MR......... 90

Tabela 3.1b: Datas e tempos de cura dos corpos-de-prova do Ensaio de MR.......... 91

Tabela 3.2: Datas e tempos de cura dos corpos-de-prova dos Ensaios de

Deformação Permanente................................................................................ 93

Tabela 4.1: Resultados da Massa Específica dos Grãos......................................... 100

Tabela 4.2: Resultados das Análises Granulométricas dos materiais deste estudo... 102

Tabela 4.3: Classificação SUCS dos materiais desta pesquisa................................. 103

Tabela 4.4: Classificação HRB dos materiais estudados nesta

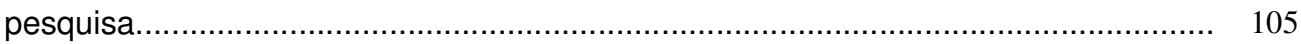

Tabela 4.5: Elementos Químicos presentes nas Cinzas e Misturas deste estudo..... 106

Tabela 4.6: Componentes Químicos das Misturas deste estudo........................... 109

Tabela 4.7: Resultados Analíticos do Ensaio de Lixiviação - Parâmetros

Inorgânicos (TASQA, 2010)...................................................................... 110

Tabela 4.8: Resultados Analíticos do Ensaio de Lixiviação - Parâmetros

Orgânicos (TASQA, 2010)........................................................................... 111

Tabela 4.9: Resultados Analíticos do Ensaio de Solubilização - Parâmetros

Inorgânicos (TASQA, 2010)........................................................................... 111

Tabela 4.10: Resultados Analíticos do Ensaio de Solubilização - Parâmetros

Orgânicos (TASQA, 2010)........................................................................... 111

Tabela 4.11: Resultados dos Ensaios de Compactação dos materiais deste estudo. 111

Tabela 4.12a: Coeficientes do Modelo Composto pelo Programa STATISTICA para

os módulos de resiliência dos matérias deste estudo............................................ 121

Tabela 4.16b: Coeficientes do Modelo Composto pelo Programa STATISTICA para

os módulos de resiliência dos materiais deste estudo............................................ 122

Tabela 4.13: Resultados dos Ensaios de Deformação Permanente de alguns

materiais deste estudo.

Tabela 4.14: Coeficientes do Modelo Composto utilizados no SisPav para

representar os materiais do presente estudo.

Tabela 4.15: Espessura da Camada de Base em função da Vida Útil do Projeto para o solo ou mistura estudados... 


\section{Lista de quadros}

Quadro 2.1: Classificação das Pozolanas segundo NBR 12653/1999 e

características gerais das cinzas brasileiras (Fonte: Rohde et al., 2006).

Quadro 2.2: Características da cinza volante e pesada, produtos, vantagens

(Fonte:Pozzobon,1999)

Quadro 2.3: Composição Média das Cales Brasileiras (Fonte: Guimarães, 2002)

Quadro 2.4: Previsão da quantidade de cal em função dos diferentes tipos de solo (Fonte: Ingles \& Metcalf, 1972 apud Sandroni \& Consoli, 2010)

Quadro 2.5: Aplicações de Misturas com Cinzas de Fundo em Projetos de Pavimentação (Fonte: Schroeder, 1994 apud Farias, 2005).

Quadro 3.1: Especificações dos Carvões Energéticos Brasileiros. (Fonte: Portaria 100/1987 - CNP)

Quadro 3.2: Exigências Físicas e Químicas da Cal (Fonte: Sandroni \& Consoli, 2010).

Quadro 3.3: Níveis de tensões utilizados durante o Ensaio Triaxial de Cargas Repetidas (Fonte: Medina \& Motta, 2005).

Quadro 4.1: Componentes Químicos das Cinzas de Fundo e Volante determinados por Mendonça (2004) (Fonte: Ubaldo, 2005).

Quadro 4.2: Concentração dos principais constituintes das cinzas de fundo e volante de diferentes procedências (Fonte: Chies (2003, apud Ubaldo, 2005))......... 


\section{Lista de abreviaturas}

$\begin{array}{ll}\text { RCD } & \text { Resíduo de Construção e Demolição } \\ \text { DNER } & \text { Departamento Nacional de Estradas e Rodagem } \\ \text { DNIT } & \text { Departamento Nacional de Infraestrutura de Transportes } \\ \text { ABNT } & \text { Associação Brasileira de Normas Técnicas } \\ \text { EPE } & \text { Empresa Pesquisa Energética } \\ \text { ASTM } & \text { American Society for Testing and Materials } \\ \text { CELUSA } & \text { Centrais Hidrelétricas de Urubupunga S.A } \\ \text { CSH } & \text { Silicato Hidratado de Cálcio } \\ \text { CAH } & \text { Aluminato Hidratado de Cálcio } \\ \text { ISC ou CBR } & \text { Índice de Suporte Califórnia } \\ \text { RSU } & \text { Resíduos Sólidos Urbanos } \\ \text { FHWA } & \text { Federal Highway Administration } \\ \text { AASHTO } & \text { American Association of State Highway and Transportation Officials } \\ \text { IPR } & \text { Instituto de Pesquisas Rodoviárias } \\ \text { DRM } & \text { Departamento de Recursos Minerais } \\ \text { SATC } & \text { Associação Beneficiente da Indústria Carbonífera de Santa Catarina } \\ \text { CNP } & \text { Conselho Nacional do Petróleo } \\ \text { CE } & \text { Carvão Energético } \\ \text { EDX } & \text { Espectrômetro de fluorescência de Raios-X por Energia Dispersiva } \\ \text { LVDT } & \text { Linear variable differential transformer } \\ \text { HRB } & \text { Highway Research Board } \\ \text { MEAS } & \text { Massa Específica Aparente Seca } \\ \end{array}$




\section{Lista de símbolos}

$\begin{array}{ll}\text { MR } & \text { Módulo de resiliência } \\ \sigma_{d} & \text { Tensão desviadora } \\ \varepsilon_{r} & \text { Deformação Vertical Resiliente } \\ \sigma_{3} & \text { Tensão confinante } \\ \mathrm{S} & \text { Solo } \\ \mathrm{CF} & \text { Cinza de Fundo } \\ \mathrm{CV} & \text { Cinza Volante } \\ \mathrm{LL} & \text { Limite de Liquidez } \\ \mathrm{LP} & \text { Limite de Plasticidade } \\ \mathrm{IP} & \text { Índice de Plasticidade } \\ D_{t} & \text { Densidade Real dos Grãos a Temperatura t } \\ k_{24} & \text { razão entre a densidade relativa da água a temperatura t e a } 20^{\circ} \mathrm{C}, \text { tabelada } \\ G_{s} & \text { na norma. } \\ \mathrm{MO} & \text { Massa Específica Real do s Grãos } \\ \mathrm{A} & \text { Teor de Matéria Orgânica } \\ \mathrm{B} & \text { massa da amostra seca em estufa, à temperatura de } 105 \text { a } 110^{\circ} \mathrm{C}(\mathrm{g}) \\ w_{o t} & \text { massa da amostra queimada em mufla, à temperatura de } 440^{\circ} \mathrm{C}(\mathrm{g}) \\ \rho_{d m a ́ x} & \text { Umidade ótima } \\ k_{1}, k_{2}, k_{3} & \text { Mator Campo Laboratório } \\ N_{f} & \text { Coeficientes de Regressão } \\ \mathrm{fcl}_{t} & \text { Vida de Fadiga } \\ & \end{array}$


"Só existem dois dias no ano em que nada pode ser feito. Um se chama ontem e outro se chama amanhã, portanto, hoje é o dia certo para amar, acreditar, fazer e principalmente viver."

Dalai Lama

"Sábio é aquele que conhece os limites da própria ignorância." 